\title{
Screening of autochthonous lactic acid bacteria strains from artisanal soft cheese: probiotic characteristics and prebiotic metabolism
}

\author{
Santiago Ruiz-Moyano ${ }^{\mathrm{a}, \mathrm{b}, *}$, María Teresa P. Gonçalves dos Santos ${ }^{\mathrm{c}}$, Ana I. Galván ${ }^{\mathrm{b}, \mathrm{d}}$, \\ Almudena V. Merchán ${ }^{\mathrm{a}, \mathrm{b}}$, Elena González ${ }^{\mathrm{b}, \mathrm{e}}$, María de Guía Córdoba ${ }^{\mathrm{a}, \mathrm{b}}$, María José Benito ${ }^{\mathrm{a}, \mathrm{b}}$

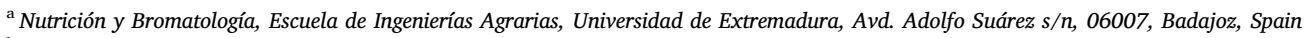 \\ ${ }^{\mathrm{b}}$ Instituto Universitario de Investigación en Recursos Agrarios (INURA), Avd. De la Investigación s/n, Universidad de Extremadura, 06006, Badajoz, Spain \\ ${ }^{\mathrm{c}}$ Instituto Politécnico de Beja, Escola Superior Agrária, Beja, Portugal \\ ${ }^{\mathrm{d}}$ Centro de Investigación Finca La Orden-Valdesequera (CICYTEX), Área de Hortofruticultura, Junta de Extremadura, Autovía Madrid-Lisboa s/n, O6187, Badajoz, Spain \\ ${ }^{\text {e }}$ Producción Animal, Escuela de Ingenierías Agrarias, Universidad de Extremadura, Avd. Adolfo Suárez s/n, 06007, Badajoz, Spain
}

A R T I C L E I N F O

\section{Keywords:}

Lactic acid bacteria

Probiotic

Prebiotic

Traditional cheese

Functional food

\begin{abstract}
A B S T R A C T
Today's growing interest in functional foods is due to their positive impacts on human health. The aim of this study was to evaluate the probiotic properties and prebiotic metabolism of autochthonous lactic acid bacteria from artisanal Serpa cheese. Twenty strains presented better tolerance to stress conditions found in the gastrointestinal tract, highlighting Lactobacillus brevis C1Lb21 for its adequate auto-aggregating ability and significantly higher hydrophobicity. However, eight strains were discarded for their antibiotic resistance and biogenic amine production. Finally, prebiotic fermentation study showed that lactulose supported better growth of lactobacilli and induced the production of short-chain fatty acids (SCFA). During lactulose fermentation, $L b$. pentosus G4Lb7 produced statistically more SCFA, and $L b$. plantarum G1Lb5 lactic acid. Thus, Lb. brevis C1Lb21, Lb. plantarum G1Lb5 and $L b$. pentosus G4Lb7 are promising probiotic candidates, and in combination with lactulose could be used for developing a symbiotic cheese.
\end{abstract}

\section{Introduction}

Nowadays, there is a growing interest in nutrition to improve health. Food is not only intended to provide the necessary nutrients but also to beneficially impact on consumers' health (Linares et al., 2017). This matter has increased the awareness and demand for functional food, mainly probiotics, due to the extensive information about their beneficial effects. Lactic acid bacteria (LAB) are the most common microorganisms applied as probiotics. They are a desirable member of the gastrointestinal tract (GIT) microbiota and have the GRAS "Generally Recognised As Safe" status (Linares et al., 2017). Several LAB species have shown probiotic characteristics and it is well-known that they are strain-dependent (Vasiljevic \& Shah, 2008). Fermented dairy products have been by far the most investigated as a source of probiotics.

Serpa cheese is a soft-cheese produced in the south of Portugal. In our previous research, the microbial community of this artisanal cheese have been described (Gonçalves Dos Santos, Benito, Córdoba, Alvarenga, \& Ruiz-Moyano, 2017; Gonçalves Dos Santos et al., 2018) and $\mathrm{LAB}$ were undoubtedly the main microbial group, with viable counts of around $10^{8} \mathrm{cfu}^{-1}$ at the end of the ripening process. LAB are involved in the ripening process of the cheese and contribute to the final organoleptic properties (O'Sullivan \& Cotter, 2017). Additionally, the LAB strains present in Serpa cheese may possess probiotic potential.

The primary criteria for selecting strains as suitable probiotics are (i) survival to GIT conditions, (ii) ability to adhere to the intestinal mucosa and colonise the colon, at least temporarily, (iii) capacity to exert potential health benefits on the host, and (iv) verified safety. Another important activity of probiotics is the fermentation of non-digestible carbohydrates into short-chain fatty acids (SCFA), mainly acetate, propionate and butyrate. There is a plethora of evidence regarding the positive benefits of these compounds on human energy metabolism, health and protection against colorectal cancer, inflammatory bowel disorders, obesity and other diseases (LeBlanc et al., 2017; Ríos-Covián et al., 2016). Therefore, studies to select probiotics with an enhanced ability to produce SCFA are relevant.

In addition to probiotic characteristics, it also desirable that these microorganisms are adapted to the fermentation process and storage. Probiotic products should be consumed regularly with an approximate amount of $100 \mathrm{~g} /$ day to deliver about $10^{9}$ viable cells into the intestine

\footnotetext{
* Corresponding author. Nutrición y Bromatología, Escuela de Ingenierías Agrarias, Universidad de Extremadura, Avd. Adolfo Suárez s/n, 06007, Badajoz, Spain.

E-mail address: srmsh@unex.es (S. Ruiz-Moyano).
} 
Table 1

Selected LAB isolates from Serpa cheese to study probiotic characteristics.

\begin{tabular}{lll}
\hline \multicolumn{2}{l}{ Selected LAB from Serpa cheese (Gonçalves et al., 2017) } \\
\hline Species & $\mathrm{N}^{\mathrm{o}}$ isolates & Code of acid-tolerant strains \\
\hline Lactobacillus casei/paracasei & 34 & V1LB8, A2Lb1 \\
Lactobacillus plantarum & 16 & C1Lc12, G4Lb1, G2Lb12, B1Lb12, \\
& & G1Lb5, G2Lb9 \\
Lactobacillus brevis & 12 & V1Lb10, B1Lb3, C1Lb21, B2Lb5 \\
Lactobacillus curvatus & 4 & - \\
Lactobacillus crustorum & 4 & A3Lb18, V1Lb9 \\
Lactobacillus coryniformi & 2 & - \\
Lactobacillus pentosus & 2 & G4Lb7 \\
Leuconostoc mesenteroides & 12 & - \\
Lactococcus lactis & 2 & - \\
Enterococcus faecium & 14 & V2Lb3, A1Lb9, G1Et4 \\
Enterococcus hirae & 12 & G3Et3 \\
Enterococcus durans & 2 & G1Et3 \\
\hline
\end{tabular}

in order to positively influence consumer health (Tripathi \& Giri, 2014). Cheese is an excellent food matrix to transport probiotic, due to its specific physical and chemical characteristics, such as $\mathrm{pH}$ between 5 and 6, high fat content and nutrient availability, and low oxygen content. Since these conditions favour their survival through gastrointestinal transit, the application of probiotics has been optimised in different types of cheeses (Albenzio et al., 2013; Minervini et al., 2012). Therefore, this study aimed to evaluate probiotic properties and prebiotic metabolism of autochthonous LAB isolated from artisanal Serpa cheese, for potential application during its manufacturing process.

\section{Material and methods}

\subsection{Bacterial isolates}

A total of $116 \mathrm{LAB}$ belonging to the Lactobacillus, Lactococcus, Leuconostoc and Enterococcus genera, isolated from Serpa cheese (Gonçalves et al., 2017), were selected to study their probiotic characteristics (Table 1). LAB were routinely grown in de Man-Rogosa-Sharpe (MRS; Scharlab, Barcelona, Spain) broth at $37^{\circ} \mathrm{C}$ under $10 \%$ $\mathrm{CO}_{2}$ for $24 \mathrm{~h}$. All strains were sub-cultured twice before the experiments, harvested at $21,500 \times g$ for $5 \mathrm{~min}$ at room temperature, washed twice with phosphate-buffered saline (PBS; Thermo Fisher Scientific, Waltham, MA, USA) at $\mathrm{pH} 7.2$, and the cell concentration adjusted to around $10^{8} \mathrm{cfu} \mathrm{mL}^{-1}$. For all strains, three biological replicates of the cultures and duplicate assays were conducted.

\subsection{Probiotic assays in vitro}

\subsubsection{Tolerance to simulated GIT}

To evaluate the acid tolerance of the LAB in vitro, they were exposed to a pH between 2.5 and 3.0 for $2 \mathrm{~h}$. Each isolate was incubated for $2 \mathrm{~h}$ in PBS supplemented with $3.5 \mathrm{~g} \mathrm{~L}^{-1}$ of pepsin, and the $\mathrm{pH}$ adjusted to $2.5,2.75,3.0$ or 5.0 (positive control) and measured by counting following the method described by Ruiz-Moyano, Martín, Benito, Nevado, and Córdoba (2008).

The strains resistant to low $\mathrm{pH}$ were used to determine the survival during complete gastrointestinal transit, by the method of Bao et al. (2010). Briefly, $30 \mu \mathrm{L}$ of concentrated strains were inoculated in $270 \mu \mathrm{L}$ of simulated gastric fluid $\left(3.5 \mathrm{~g} \mathrm{~L}^{-1}\right.$ porcine pepsin ( $\geq 400 \mathrm{Units} / \mathrm{mg}$ protein) and $2 \mathrm{~g} \mathrm{~L}^{-1} \mathrm{NaCl}$ ) at $\mathrm{pH} 2.75$ for $2 \mathrm{~h}$. Then $30 \mu \mathrm{L}$ were transfer to $270 \mu \mathrm{L}$ of in simulated intestinal fluid $\left(1 \mathrm{~g} \mathrm{~L}^{-1}\right.$ trypsin, $5 \mathrm{~g} \mathrm{~L}^{-1}$ bile salt, $2 \mathrm{~g} \mathrm{~L}^{-1}$ pancreatin [all from Sigma St. Louis, MO, USA], $11 \mathrm{~g} \mathrm{~L}^{-1}$ $\mathrm{NaHCO}_{3}$ and $2 \mathrm{~g} \mathrm{~L}^{-1} \mathrm{NaCl}$ ) at $\mathrm{pH} 8$ during $6 \mathrm{~h}$. The 96 micro-well plates were incubated at $37{ }^{\circ} \mathrm{C}$ under $10 \% \mathrm{CO}_{2}$, and the viable bacteria were counted on MRS media after 0, 2, 4 and $6 \mathrm{~h}$. Data were expressed in Log cfu $\mathrm{mL}^{-1}$ reduction with respect to the initial inoculum (Time $0 \mathrm{~h}: 8$
Log cfu $\mathrm{mL}^{-1}$ ). Strains with viable counts below $2 \log$ cfu $\mathrm{mL}^{-1}$ compared with the initial inoculums were considered not resistant.

\subsubsection{Aggregation activity}

The specific cell-cell interactions were determined using the autoaggregation assay described by Xu, Jeong, Lee, and Ahn (2009). The auto-aggregation was calculated using the following equation:

Auto-aggregation $(\%)=\left(1-A_{t} / A_{o}\right) \times 100$

where $A_{t}$ represents absorbance at a determined interval ( 1 or $2 \mathrm{~h}$ ); and $A_{O}$ represents the absorbance at the beginning of the assay $(0 \mathrm{~h})$.

\subsubsection{Cell surface hydrophobicity}

The cell surface hydrophobicity was determined as described Lee and Puong (2002). The decreased absorbance in the aqueous phase was taken as a measure of cell surface hydrophobicity, calculated using the following equation:

Hydrophobicity $(\%)=[(A O-\mathrm{A} 1) / A O] \times 100$

where $A 0$ and $A 1$ are the absorbance values before and after extraction with $n$-hexadecane, respectively.

\subsection{Safety assays}

\subsubsection{Antibiotic susceptibility}

The selected acid-tolerant strains were tested for antibiotic susceptibility by the disc diffusion method according to the National Committee for Clinical Laboratory Standards (NCCLS, 2012). Twelve clinically important antibiotics (Oxoid, Basingstoke, England) were used: ampicillin $(10 \mu \mathrm{g})$, gentamicin $(10 \mu \mathrm{g})$, kanamycin $(30 \mu \mathrm{g})$, trimethoprim $(5 \mu \mathrm{g})$, erythromycin $(15 \mu \mathrm{g})$, tetracycline $(30 \mu \mathrm{g})$, clindamycin $(2 \mu \mathrm{g})$, chloramphenicol $(30 \mu \mathrm{g})$, penicillin G (10 U), polymyxin B (300 U), nalidixic acid $(30 \mu \mathrm{g})$ and vancomycin $(30 \mu \mathrm{g})$. The diameters of the inhibition zones were measured and the results interpreted according to the criteria proposed by Charteris, Kelly, Morelli, and Collins (1998).

\subsubsection{Biogenic amine $(B A)$ production}

The capacity of selected strains to produce BA was determined by the improved agar medium, as described by Bover-Cid and Holzapfel (1999). Moreover, the amount and type of BA produced in the improved medium (Bover-Cid \& Holzapfel, 1999), without agar and containing $0.25 \%$ of each precursor amino acid after incubation for 4 days at $37^{\circ} \mathrm{C}$ and $10 \% \mathrm{CO}_{2}$ was measured by high-performance liquid chromatography (HPLC)-electrospray ionisation (ESI)-mass spectrometry, according to the method described by Fernández et al. (2016). BA in samples was distinguished by their mass spectrum and retention time.

\subsection{Growth on prebiotic}

The LAB selected on the basis of their probiotic properties were tested for growth in the presence of three commercial prebiotics; lactulose (Sigma), short-chain fructooligosaccharide (FOS, Orafti ${ }^{\circ}$ P95 with a degree of polymerisation (DP) $2-8$, Beneo-Orafti, Belgium) and long-chain inulin (Orafti ${ }^{\odot}$ GR with DP $2-60$ and average DP $\geq 10$, Beneo-Orafti). Two $\mu \mathrm{L}$ of each LAB strain suspension was inoculated in $200 \mu \mathrm{L}$ of semi-solid MRS medium containing $0.125 \mathrm{~g} \mathrm{~L}^{-1}$ agar, devoid of glucose, and supplemented with $2 \mathrm{~g} \mathrm{~L}^{-1}$ of each sterile-filtered prebiotic, as the sole carbohydrate source. The positive control for growth consisted of semi-solid MRS supplemented with $2 \mathrm{gL}^{-1}$ glucose or lactose, whereas the negative control was a carbohydrate-free semisolid MRS. The automated turbidimeter Bioscreen C Microbiology reader (Labsystem, Helsinki, Finland) set up at $37^{\circ} \mathrm{C}$ was used to monitor the growth for $96 \mathrm{~h}$ by reading the optical density (OD) at 
$600 \mathrm{~nm}$ at regular intervals without shaking. The ability of each strain to grow in the presence of different prebiotics was evaluated by comparing the OD at $600 \mathrm{~nm}$ of each carbohydrate with the value obtained on glucose.

\subsection{SCFA production}

To determine the capacity to produce SCFA, selected LAB strains were grown on modified MRS (mMRS) broth at $37^{\circ} \mathrm{C}$ under $10 \% \mathrm{CO}_{2}$ until stationary phase. The mMRS was formulated as commercial MRS devoid of glucose and sodium acetate and supplemented with $2 \mathrm{~g} \mathrm{~L}^{-1}$ of the carbohydrate source (glucose, lactose, lactulose, FOS or inulin). The supernatants of the cultures were obtained by centrifugation of the media at $8000 \times g$ for $5 \mathrm{~min}$ before filtering through $0.22-\mu \mathrm{m}$ filters (Thermo Fisher Scientific).

The concentration of lactic acid (D- and L-isomers) in the supernatant was quantified using the enzymatic kit K-DLATE (Megazyme, Bray, Ireland) according to the manufacturer's instructions.

To measure the amount of SCFA, $800 \mu \mathrm{L}$ of supernatant was mixed with $100 \mu \mathrm{L}$ of internal standard solution (2-ethyl butyric acid [Sigma] at $5 \mathrm{mM}$ prepared in $12 \%$ formic acid) and $100 \mu \mathrm{L}$ of meta-phosphoric acid solution $\left(16 \mathrm{~g} \mathrm{~L}^{-1}\right)$. SCFA were extracted with $500 \mu \mathrm{L}$ of diethyl ether by vortexing for $1 \mathrm{~min}$ and centrifugation at $17,000 \times g, 4^{\circ} \mathrm{C}$ for $5 \mathrm{~min}$. One microlitre of the upper phase was injected into a gas chromatograph (model 4890 Series II; Hewlett-Packard, Palo Alto, CA, USA) equipped with a split/split-less injector and a flame ionisation detector. SCFA were separated on a Carbowax ${ }^{\mathrm{TM}}$ fused silica capillary column ( $30 \mathrm{~m} \times 0.25 \mathrm{~mm}$ id; $0.25 \mu \mathrm{m}$ film thickness; (Ohio Valley, Marietta, $\mathrm{OH}$, USA). The initial oven temperature was held at $80^{\circ} \mathrm{C}$ for $2 \mathrm{~min}$, and then increased to $200{ }^{\circ} \mathrm{C}$ at $20^{\circ} \mathrm{C} \mathrm{min}{ }^{-1}$ and retained for $12 \mathrm{~min}$. The injector and detector were set at $250^{\circ} \mathrm{C}$. The carrier gas was nitrogen at $1.8 \mathrm{~mL} \mathrm{~min}^{-1}$. The individual SCFA were identified by comparison of their retention times with those of reference standard mixtures (acetic acid, propionic acid, butyric acid, isobutyric acid, valeric acid, isovaleric acid, hexanoic acid from Sigma Chemical Co., St Louis, MO, USA). SCFA concentrations were calculated by using the peak area ratio of the analyte to the internal standard (2-ethyl butyric acid), as detailed by Brighenti (1997).

\subsection{Statistical analysis}

Auto-aggregating and hydrophobicity data were analysed by oneway analysis of variance (ANOVA), and SCFA production by two-way ANOVA, respectively, using SPSS for Windows 21.0 (SPSS, Inc., Chicago, IL, USA). The means were separated by Tukey's honestly significant difference (HSD) test $(p \leq 0.05)$.

\section{Results and discussion}

\subsection{Tolerance to the GIT conditions}

All LAB isolates tolerated $\mathrm{pH}$ 3.0. When the isolates were exposed to $\mathrm{pH} 2.5$, none survived at the levels required. At an intermediate $\mathrm{pH}$ (2.75), 20 of the 116 strains exhibited satisfactory levels of viability after exposure for $2 \mathrm{~h}$ (Table 2). Previous authors have reported that the viability of LAB is dramatically affected at low $\mathrm{pH}$, especially below $\mathrm{pH}$ 2.5 (Zoumpopoulou et al., 2018). The acid tolerance of LAB is strain specific and mediated via several mechanisms, in particular, F0F1-ATPase is an important element in the response and tolerance to low $\mathrm{pH}$ in Lactobacillus spp. (Corcoran, Stanton, Fitzgerald, \& Ross, 2005). In this study, a $\mathrm{pH}$ value of 2.75 was found to be highly discriminating and although the $\mathrm{pH}$ of the stomach during a meal is normally above this value, this value was set in order to guarantee the viability of the potential probiotic strains.

The acid-tolerant strains were subjected to in vitro digestion. Most of the selected strains showed good survival to complete GIT transit
(Table 2). However, two of the twenty strains, Lb. casei/paracasei strains V1Lb8 and A2Lb1, decreased their viability dramatically when they were exposed to simulated gastric fluid at $\mathrm{pH} 2.75$ for $90 \mathrm{~min}$, followed by $120 \mathrm{~min}$ in simulated intestinal fluid. These results are consistent with those previously recovered from other probiotic in vitro testing where most of the strains were more resistant to bile salts than low $\mathrm{pH}$ (Han, Kong, Chen, Sun, \& Zhang, 2017; Ruiz-Moyano et al., 2008; Zoumpopoulou et al., 2018).

\subsection{Capacity to colonise the intestine}

The percentage of auto-aggregation after incubation for 1 and $2 \mathrm{~h}$ are presented in Fig. 1A. In general, the values varied between 1.43 and $9.14 \%$ at $1 \mathrm{~h}$, and $2.70-17.14 \%$ at $2 \mathrm{~h}$, respectively. All strains increased the auto-aggregation percentages with the incubation time, in congruence with other researchers (García-Cayuela et al., 2014; Han et al., 2017). Among strains, significant differences were observed $(p \leq 0.05)$. At $2 \mathrm{~h}$, seven of the twenty strains, Lb. brevis C1Lb21 and B2Lb5, Lb. crustorum A3Lb18, E. faecium V2Lb3, A1Lb9 and G1Et4, and E. durans G1Et3, exhibited better auto-aggregation, with values over $12 \%$, corresponding to a noteworthy capacity based upon previous studies in LAB (García-Cayuela et al., 2014; Han et al., 2017).

There was high variability in the hydrophobicity capacity, which ranged from 5.42 to $76.50 \%$ (Fig. 1B). Lb. brevis C1Lb21 exhibited the highest hydrophobicity (76.50\%). The results obtained for both cell surface properties did not always show the same trend in each strain, as already noted by García-Cayuela et al. (2014). Adhesion is a very complex mechanism influenced by multiple factors. Auto-aggregation capacity is afforded by complex physical and chemical interactions, as well as being influenced by environmental conditions (Collado, Meriluoto, \& Salminen, 2008; García-Cayuela et al., 2014; Goh \& Klaenhammer, 2010).

\subsection{Safety aspects}

\subsubsection{Antibiotic susceptibility}

Nowadays, antibiotic resistance is considered a serious concern in medicine. According to the European Food Safety Authority (EFSA), intrinsic resistance in bacteria present a minimal risk for horizontal spread whereas acquired resistance is considered a high risk (EFSA, 2012). The antibiotic susceptibility of selected LAB strains against 12 common antibiotics is shown in Table S1. All lactobacilli strains were found susceptible or moderately susceptible to penicillin G, chloramphenicol, erythromycin, tetracycline, ampicillin, gentamycin and clindamycin. In addition, it was found resistance of 11 lactobacilli strains to kanamycin, all $L b$. brevis and $L b$. casei/paracasei strains to polymyxin $\mathrm{B}$, and three strains, $L b$. brevis $\mathrm{B} 1 \mathrm{Lb} 2, L$. casei/paracasei V1lb8 and A2Lb1, to trimethoprim. In general, although there may be differences between species and strains, most Lactobacillus spp. are considered to be naturally resistant to vancomycin, nalidixic acid, kanamycin, polymyxin B and trimethoprim. In this context, the observed patterns of antibiotic susceptibility agree with the results obtained in the literature for these lactobacilli species, and they can be used in fermented food (Abriouel et al., 2015). The resistance profiles of enterococci from food or clinical isolates vary widely, containing many acquired traits. Enterococci are naturally resistant to cephalosporins, low level aminoglycosides (kanamycin and gentamycin), polymixins, lincomycin, clindamycin and often quinolones (nalidixic acid) (Sharma, Tomar, Goswami, Sangwan, \& Singh, 2014). The major concern was the detection of acquired resistance to trimethoprim in three enterococci strains, G3Et3, A1Lb9 and V2Lb3, and especially to relevant clinical antibiotics, such as tetracycline (in two strains, A1Lb9 and G3Et3) and vancomycin (in G1Et4). Consequently, these enterococci strains were not selected. 
Table 2

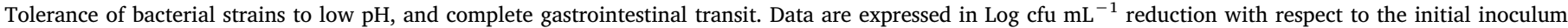
(Time 0 h: 8 Log cfu $\mathrm{mL}^{-1}$ ).

\begin{tabular}{|c|c|c|c|c|c|c|c|c|}
\hline \multirow[t]{3}{*}{ LAB strains } & & \multicolumn{3}{|c|}{$\mathrm{pH}$ tolerance $(2.75)$} & \multicolumn{4}{|c|}{ Tolerance to gastointestinal transit } \\
\hline & & \multirow[b]{2}{*}{$1 \mathrm{~h}$} & \multirow[b]{2}{*}{$1.5 \mathrm{~h}$} & \multirow[b]{2}{*}{$2 \mathrm{~h}$} & \multirow[t]{2}{*}{ Gastric juice (pH2.75) $1.5 \mathrm{~h}$} & \multicolumn{3}{|c|}{ Intestinal juice } \\
\hline & & & & & & $2 \mathrm{~h}$ & $4 \mathrm{~h}$ & $6 \mathrm{~h}$ \\
\hline \multirow[t]{6}{*}{ Lb. plantarum } & C1Lc12 & 0 & 0 & 0 & 0 & 1 & 1 & 1 \\
\hline & G4Lb1 & 1 & 1 & 2 & 0 & 0 & 0 & 0 \\
\hline & G2Lb12 & 0 & 1 & 1 & 0 & 0 & 0 & 0 \\
\hline & B1Lb2 & 0 & 1 & 1 & 1 & 1 & 1 & 2 \\
\hline & G1Lb5 & 1 & 1 & 1 & 0 & 0 & 0 & 0 \\
\hline & G2Lb9 & 1 & 1 & 2 & 1 & 1 & 1 & 1 \\
\hline \multirow[t]{4}{*}{ Lb. brevis } & V1Lb10 & 0 & 1 & 1 & 1 & 2 & 2 & 3 \\
\hline & B1Lb3 & 1 & 1 & 1 & 0 & 0 & 0 & 0 \\
\hline & C1Lb21 & 0 & 0 & 0 & 0 & 1 & 1 & 1 \\
\hline & B2Lb5 & 0 & 0 & 1 & 0 & 1 & 1 & 1 \\
\hline \multirow[t]{2}{*}{ Lb. casei/paracasei } & V1Lb8 & 1 & 2 & 2 & 2 & 3 & 5 & 8 \\
\hline & A2Lb1 & 1 & 1 & 1 & 1 & 3 & 4 & 7 \\
\hline \multirow[t]{2}{*}{ Lb. crustorum } & A3Lb18 & 0 & 1 & 1 & 0 & 0 & 1 & 1 \\
\hline & V1Lb9 & 0 & 1 & 1 & 0 & 0 & 0 & 0 \\
\hline Lb. pentosus & G4Lb7 & 1 & 1 & 2 & 1 & 1 & 1 & 1 \\
\hline \multirow[t]{3}{*}{ E. faecium } & V2Lb3 & 0 & 1 & 1 & 0 & 0 & 0 & 0 \\
\hline & A1Lb9 & 1 & 1 & 1 & 1 & 1 & 1 & 1 \\
\hline & G1Et4 & 0 & 0 & 0 & 0 & 0 & 0 & 1 \\
\hline E. durans & G1Et3 & 0 & 0 & 0 & 0 & 0 & 0 & 0 \\
\hline E. hirae & G3Et3 & 0 & 0 & 0 & 0 & 0 & 0 & 0 \\
\hline
\end{tabular}

\subsubsection{BA production}

The ability of the LAB strains to produce BA in vitro is presented in Table S2. Of the 20 strains, three Lactobacillus spp. (Lb. brevis B1Lb3 and B2Lb5, and Lb. crustorum V1Lb9) and the five Enterococcus spp. strains were positive on the decarboxylase medium. The HPLC-MS analysis confirmed that all positive strains produced levels ranged from 523.61 to $4167.67 \mathrm{mg} \mathrm{L}^{-1}$ of tyramine and tryptamine between 1.58 and $14.46 \mathrm{mg} \mathrm{L}^{-1}$. Production of BA by potential probiotics strains is not a desirable property due to its toxic effect on consumer health (Gardini, Özogul, Suzzi, Tabanelli, \& Özogul, 2016). So, the eight positive BA amine strains were not suitable as probiotic candidate.

\subsection{Prebiotic growth and SCFA production}

The capacity of the 12 pre-selected LAB to grow in vitro on three commercial prebiotics and positive substrate controls (glucose and lactose) is showed in Fig. S1.

In general, all LAB strains reached a maximum OD $600 \mathrm{~nm}$ values in lactulose comparable to the positive controls, although $L b$. brevis C1Lb21 and V1Lb10 presented a slower growth rate and a longer lag phase. In the FOS or inulin, the growth was lower and more variable between strains than in lactulose. Interestingly, Lb. casei/paracasei V1Lb8 showed relevant growth on FOS and inulin while intermediate growth was observed in the remaining strains, except for $L b$. brevis strains $L b$. plantarum B2Lb1 and Lb. crustorum A3Lb18, which showed low ability to use these prebiotics (Fig. S1). Contrary to the expected, LAB growth was, generally, greater with inulin than FOS, despite the higher DP of inulin. We suppose that this result might be influenced by the relatively higher purity of FOS (Orafti ${ }^{\circledR}$ P95). The capacity to ferment lactulose is widespread between lactobacilli species, and $\beta$-galactosidase activity has been related to lactulose hydrolysis and metabolisation (Mao et al., 2014; Sharma \& Kanwar, 2018). However, FOS utilisation is generally more specific. Our results suggest that lactulose is a suitable prebiotic to support lactobacilli growth. In addition, this prebiotic has demonstrated to be selective to avoid pathogenic bacterial growth (Sharma \& Kanwar, 2018), improve the response of probiotics to acid and bile stresses (Adebola, Corcoran, \& Morgan, 2014) and exert a positive effect in the treatment of intestinal disorders (Gibson, Probert, Van Loo, Rastall, \& Roberfroid, 2004; Vilela, Torres, Ferrari,
Lima, \& Cunha, 2008).

Table 3 shows lactic acid and SCFA production by carbon source obtained from the mean values of the 12 selected strains. Overall, lactic acid was the principal metabolite detected ranged from $15.086 \mathrm{mM}$ in FOS to $120.697 \mathrm{mM}$ in lactose. The acetic acid ranged from $6.500 \mathrm{mM}$ in FOS to15.471 in lactulose. Small amounts of butyric, isobutyric, propionic and isovaleric acids were detected. The limited capacity of most of the LAB strains to ferment FOS and inulin was evidenced by the low lactic acid and SCFA production. Interestingly, lactulose statistically increased the production of SCFA and induced a noteworthy level of lactic acid, plus a lower ratio of D-lactic acid, which has been associated with potential health problems. SCFA display distinct positive physiological effects on the host. Butyric acid has been the most widely studied for its anti-carcinogenic and anti-inflammatory effects, although acetic acid and propionic acid also exhibit health-promoting actions (Russell, Hoyles, Flint, \& Dumas, 2013).

Regarding the strain capacity, Fig. 2 shows the mean values and statistical differences between the organic acids produced by the preselected LAB strains in lactulose and carbohydrate source controls. Significant differences $(p \leq 0.05)$ were found between strains in the amount of SCFA produced in lactulose. For all tested strains, acetic acid was the second major metabolite, with approximately 10 -fold less concentration than lactic acid, except for $L b$. pentosus G4Lb7 that produced a similar amount of both metabolites. For the remaining compounds detected, the concentrations were approximately similar to each other, with values around $0.10 \mathrm{mM}$. Besides acetic acid, $L b$. pentosus G4Lb7 also produced significantly higher $(p \leq 0.05)$ amounts of butyric, isobutyric, propionic and isovaleric acids while similar patterns were found among the other strains. Among them, Lb. casei/paracasei A2Lb1 stood out due to its high production of propionic acid comparable to $L b$. pentosus G4Lb7, and slightly higher than average amount of the other SCFA, although this strain was not resistant to GIT transit (Table 2).

With respect to lactic acid production in lactose and glucose, $L b$. plantarum G2Lb9 produced the highest amounts $(p \leq 0.05)$, with values around $175 \mathrm{mM}$, followed by a second group of strains composed of $L b$. plantarum G1Lb5, C1Lc12 and G4Lb7, Lb. casei/paracasei V1Lb8 and $L b$. pentosus G4Lb7, with values ranging from 130 to $155 \mathrm{mM}$. Lactic acid production from lactose fermentation by cheese microbiota has 


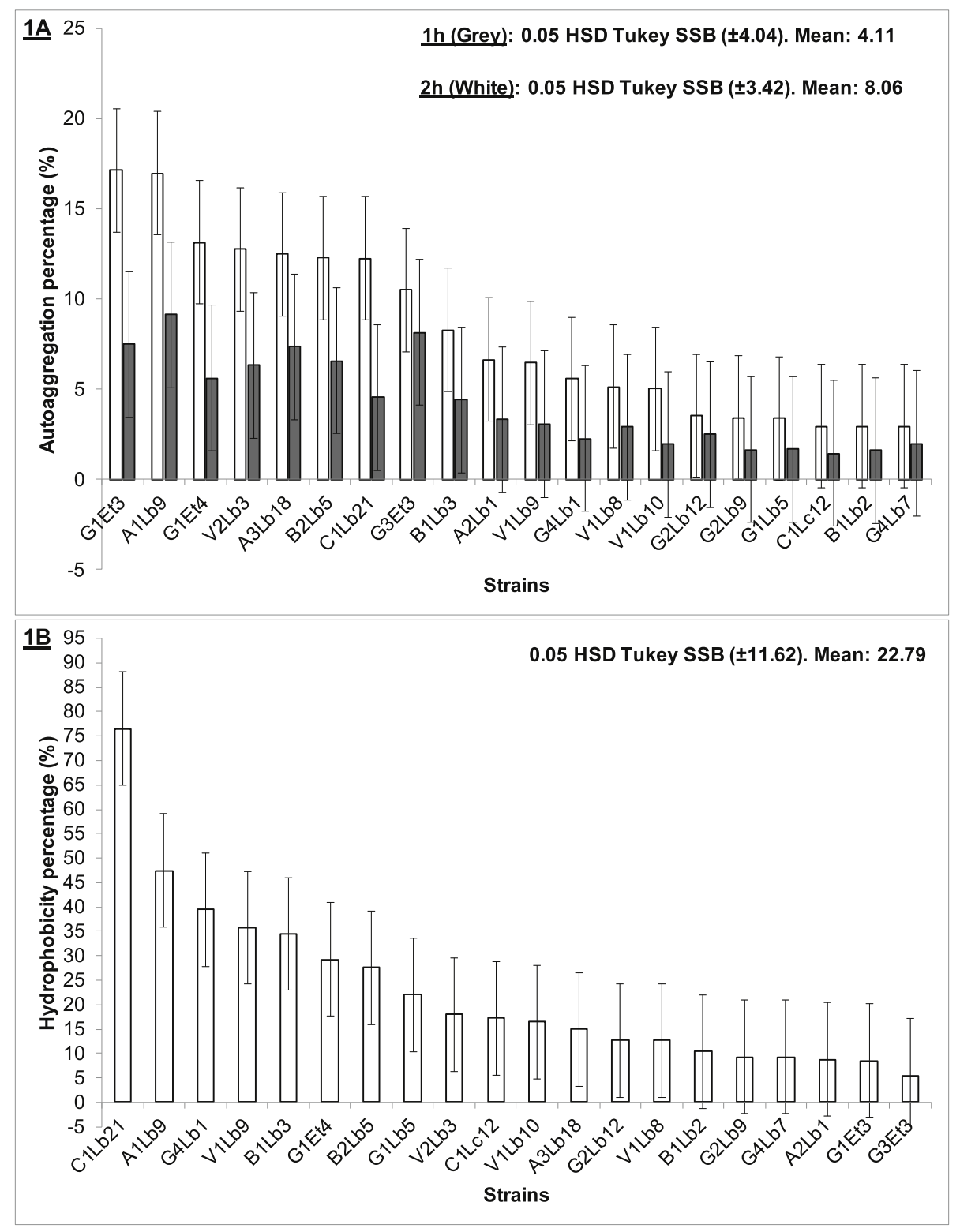

Fig. 1. (A) Auto-aggregation percentages of LAB strains after $1 \mathrm{~h}$ (grey bars) and $2 \mathrm{~h}$ (white bars) and (B) hydrophobicity capacity against hexadecane. SSB: statistical significance bar using Tukey's HSD test $(p \leq 0.05)$.

Table 3

Amount of lactic acid and short-chain fatty acids (SCFA) by carbohydrate source. Each data is the average values obtained from the 12 selected strains.

\begin{tabular}{|c|c|c|c|c|c|c|c|c|c|}
\hline \multirow[t]{2}{*}{ Carbon source } & & \multicolumn{8}{|c|}{ Organic acids (mM) } \\
\hline & & Lactic acid & L-lactic acid & D-lactic & acetic & Propionic & butyric & Isobutyric & Isovaleric \\
\hline \multirow[t]{2}{*}{ Lactose } & Mean & $120.697^{a^{*}}$ & $63.596^{b}$ & $57.100^{\mathrm{a}}$ & $7.098^{b}$ & $0.057^{b}$ & $0.0788^{b}$ & $0.051^{b}$ & $0.037^{b}$ \\
\hline & Std. Deviation & 29.517 & 21.410 & 34.518 & 3.990 & 0.010 & 0.007 & 0.014 & 0.008 \\
\hline \multirow[t]{2}{*}{ Glucose } & Mean & $116.335^{b}$ & $72.204^{\mathrm{a}}$ & $44.130^{b}$ & $6.503^{b}$ & $0.053^{b}$ & $0.079^{b}$ & $0.047^{b}$ & $0.038^{b}$ \\
\hline & Std. Deviation & 32.863 & 26.865 & 27.845 & 3.647 & 0.011 & 0.012 & 0.007 & 0.006 \\
\hline \multirow[t]{2}{*}{ Lactulose } & Mean & $92.016^{c}$ & $62.866^{b}$ & $29.149^{c}$ & $15.471^{\mathrm{a}}$ & $0.130^{\mathrm{a}}$ & $0.113^{a}$ & $0.080^{\mathrm{a}}$ & $0.055^{\mathrm{a}}$ \\
\hline & Std. Deviation & 31.265 & 28.650 & 20.246 & 4.699 & 0.078 & 0.045 & 0.051 & 0.021 \\
\hline \multirow[t]{2}{*}{ Inulin } & Mean & $21.590^{d}$ & $15.192^{\mathrm{c}}$ & $6.398^{\mathrm{d}}$ & $6.708^{b}$ & $0.049^{c}$ & $0.060^{c}$ & $0.038^{c}$ & $0.030^{c}$ \\
\hline & Std. Deviation & 30.778 & 28.255 & 6.770 & 5.322 & 0.048 & 0.044 & 0.038 & 0.022 \\
\hline \multirow[t]{2}{*}{ FOS } & Mean & $15.086^{\mathrm{e}}$ & $12.999^{c}$ & $2.086^{\mathrm{e}}$ & $6.500^{b}$ & $0.041^{\mathrm{c}}$ & $0.058^{c}$ & $0.036^{\mathrm{c}}$ & $0.027^{\mathrm{c}}$ \\
\hline & Std. Deviation & 32.633 & 32.187 & 1.843 & 5.551 & 0.030 & 0.042 & 0.037 & 0.020 \\
\hline$P \leq 0.05$ & & 0.00 & 0.00 & 0.00 & 0.00 & 0.00 & 0.00 & 0.00 & 0.00 \\
\hline Tukey HSD IC & & \pm 4.174 & \pm 3.158 & \pm 2.630 & \pm 1.299 & \pm 0.009 & \pm 0.006 & \pm 0.007 & \pm 0.005 \\
\hline
\end{tabular}

* a,b,c,d,e For a given organic acid, values (column) with different superscript letters are significantly different ( $p \leq 0.05$ ). 


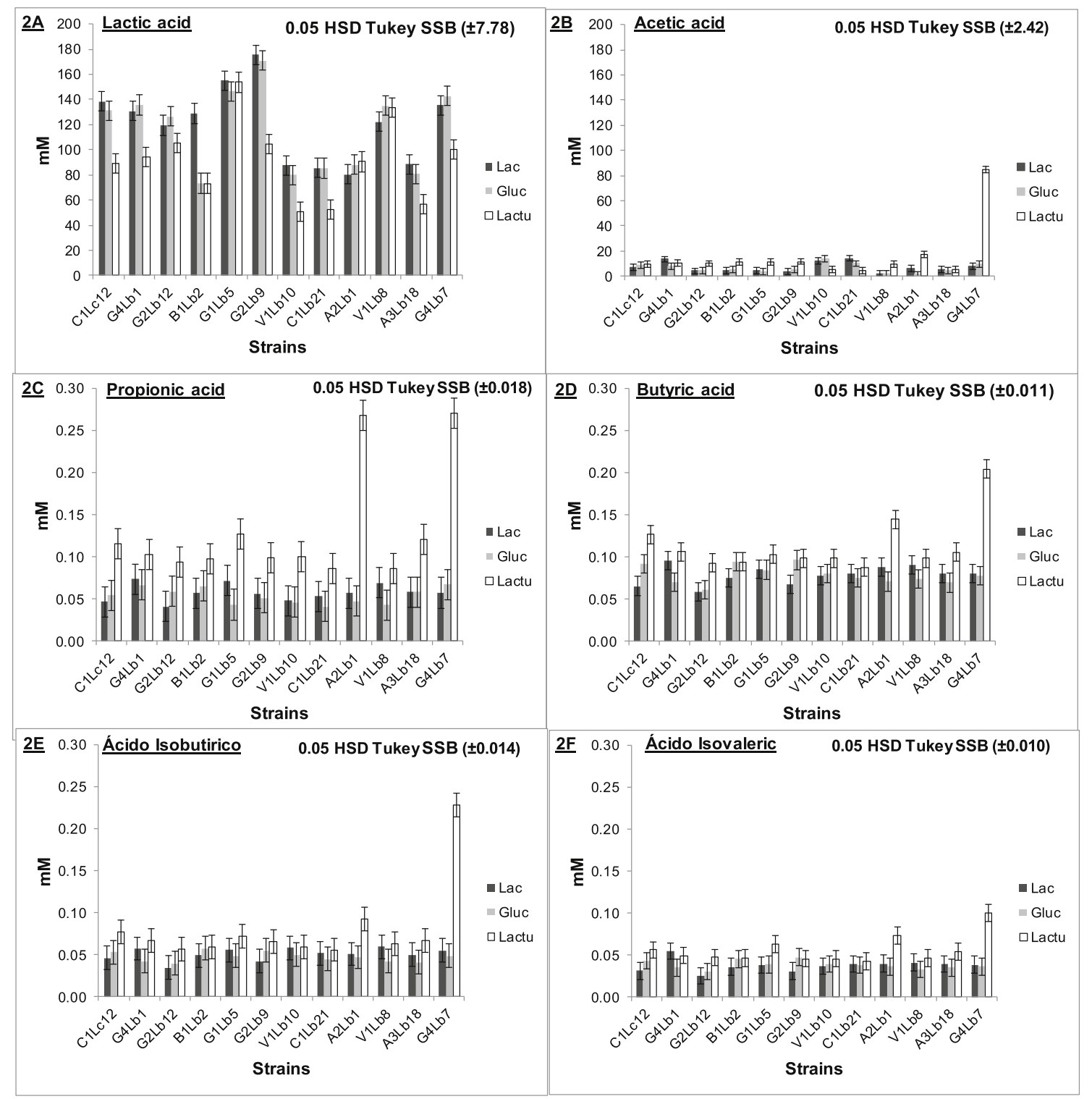

Fig. 2. Quantification of lactic acid and short-chain fatty acids by selected LAB in glucose (Gluc), lactose (Lac) and lactulose (Lactu). (A) Lactic acid, (B) acetic acid, (C) propionic acid, (D) butyric acid, (E) isobutyric acid and (F) isovaleric acid. SSB: statistical significance bar using Tukey's HSD test ( $p \leq 0.05)$.

technological applications during cheese ripening, to drop the $\mathrm{pH}$ and provide an acidic environment, which, in turn, ensures food safety and favours the coagulation process (McSweeney, 2004). In lactulose, $L b$. plantarum G1Lb5 produced the greatest amounts of lactic acid ( $p \leq 0.05$ ), reaching levels of $153 \mathrm{mM}$, without statistical difference from glucose and lactose. The other strains, except for the two Lb. casei/ paracasei, exhibited an evident decrease in the production of this metabolite. Lactulose is not consumed in the upper part of the intestine and can stimulate the growth of probiotics in the colon and lactic acid production. Although, in general, LAB produced low amounts of the most interesting SCFA for human health, it must be considered that a potential probiotic will be a member of the intestinal microbiota where it may establish possible cross-feeding interactions with lactate-consuming butyrate-producing colon bacteria (Moens, Verce, \& De Vuyst, 2017). Thus, to select a potential probiotic, aside from SCFA production capacity in assay conditions, it is also relevant to consider their ability to produce lactic acid from non-digestible oligosaccharides, as this may contribute to increasing the daily SCFA amount in the colon environment, by the activity of the intestinal microbiota.

In conclusion, considering their tolerance to gastrointestinal transit, capacity to colonise the intestine, safety properties and prebiotics metabolism, Lb. brevis C1Lb21, Lb. plantarum G1Lb5 and Lb. pentosus G4Lb7 are promising candidates for their use in a new functional cheese. The development of a symbiotic commercial cheese with lactulose prebiotic to support LAB growth and induce SCFA production could positively impact on human health.

\section{Acknowledgements}

Funding: This work was supported by the University of Extremadura (223/18); Junta Extremadura Government (ref. GR18165; IB16038); Portuguese Ministry of Agriculture and Rural Development, and European Agricultural Fund for Rural Development (EAFRD) (ref: PDR2020-101-031017; Serpaflora-Valorization of the native flora of Serpa Cheese). A.V. Merchán is funded by pre-doctoral grant from the Regional Government of Extremadura (PD16026). A.I. Galván is funded by pre-doctotal grant from Ministry of Science, Innovation and Universities (RTA2017-00032-CO2-01). 


\section{Appendix A. Supplementary data}

Supplementary data to this article can be found online at https:// doi.org/10.1016/j.1wt.2019.108388.

\section{References}

Abriouel, H., Muñoz, M. D. C. C., Lerma, L. L., Montoro, B. P., Bockelmann, W., Pichner, R., et al. (2015). New insights in antibiotic resistance of Lactobacillus species from fermented foods. Food Research International, 78, 465-481.

Adebola, O. O., Corcoran, O., \& Morgan, W. A. (2014). Synbiotics: The impact of potential prebiotics inulin, lactulose and lactobionic acid on the survival and growth of lactobacilli probiotics. Journal of Functional Foods, 10, 75-84.

Albenzio, M., Santillo, A., Caroprese, M., Braghieri, A., Sevi, A., \& Napolitano, F. (2013). Composition and sensory profiling of probiotic Scamorza Ewe milk cheese. Journal of Dairy Science, 96(5), 2792-2800.

Bao, Y., Zhang, Y., Zhang, Y., Liu, Y., Wang, S., Dong, X., et al. (2010). Screening of potential probiotic properties of Lactobacillus fermentum isolated from traditional dairy products. Food Control, 21(5), 695-701.

Bover-Cid, S., \& Holzapfel, W. H. (1999). Improved screening procedure for biogenic amine production by lactic acid bacteria. International Journal of Food Microbiology, 53(1), 33-41.

Brighenti, F. (1997). Simple method for quantitative analysis of short chain fatty acids in serum by gas-liquid chromatography. In F. Guillon,, G. Abraham,, R. Amadó,, H. Andersson,, N. G. Asp,, \& K. E. Bach Knudsen, (Eds.). Plant polysaccharides in human nutrition: Structure, function, digestive fate and metabolic affects (pp. 114-119). Nantes, France: INRA.

Charteris, W. P., Kelly, P. M., Morelli, L., \& Collins, J. K. (1998). Antibiotic susceptibility of potentially probiotic Lactobacillus species. Journal of Food Protection, 61(12), $1636-1643$.

Collado, M. C., Meriluoto, J., \& Salminen, S. (2008). Adhesion and aggregation properties of probiotic and pathogen strains. European Food Research and Technology, 226(5), 1065-1073.

Corcoran, B. M., Stanton, C., Fitzgerald, G. F., \& Ross, R. P. (2005). Survival of probiotic lactobacilli in acidic environments is enhanced in the presence of metabolizable sugars. Applied and Environmental Microbiology, 71(6), 3060-3067.

European Food Safety Authority (2012). EFSA Panel on Additives and Products or Substances used in Animal Feed (FEEDAP). Guidance on the assessment of bacterial susceptibility to antimicrobials of human and veterinary importance. EFSA Journal, 10,2740 .

Fernández, M., Ruiz-Moyano, S., Benito, M. J., Martín, A., Hernández, A., \& Córdoba, M. G. (2016). Potential antimicrobial and antiproliferative activities of autochthonous starter cultures and protease EPg222 in dry-fermented sausages. Food \& Function, 7(5), 2320-2330.

García-Cayuela, T., Korany, A. M., Bustos, I., de Cadiñanos, L. P. G., Requena, T., Peláez, C., et al. (2014). Adhesion abilities of dairy Lactobacillus plantarum strains showing an aggregation phenotype. Food Research International, 57, 44-50.

Gardini, F., Özogul, Y., Suzzi, G., Tabanelli, G., \& Özogul, F. (2016). Technological factors affecting biogenic amine content in foods: A review. Frontiers in Microbiology, 7, 1218.

Gibson, G. R., Probert, H. M., Van Loo, J., Rastall, R. A., \& Roberfroid, M. B. (2004). Dietary modulation of the human colonic microbiota: Updating the concept of prebiotics. Nutrition Research Reviews, 17(2), 259-275.

Goh, Y. J., \& Klaenhammer, T. R. (2010). Functional roles of aggregation-promoting-like factor in stress tolerance and adherence of Lactobacillus acidophilus NCFM. Applied and Environmental Microbiology, 76(15), 5005-5012.

Gonçalves Dos Santos, M. T. P., Benito, M. J., Córdoba, M. G., Alvarenga, N., \& de Herrera, S. R. M. S. (2017). Yeast community in traditional Portuguese Serpa cheese by culture-dependent and -independent DNA approaches. International Journal of Food Microbiology, 262, 63-70.

Gonçalves Dos Santos, M. T. P., Benito, M. J., Córdoba, M. G., Egas, C., Merchán, A. V., Galván, A. I., et al. (2018). Bacterial communities in Serpa cheese by culture dependent techniques, 16S rRNA gene sequencing and high-throughput sequencing analysis. Journal of Food Science, 83(5), 1333-1341.

Han, Q., Kong, B., Chen, Q., Sun, F., \& Zhang, H. (2017). In vitro comparison of probiotic properties of lactic acid bacteria isolated from Harbin dry sausages and selected probiotics. Journal of Functional Foods, 32, 391-400.

LeBlanc, J. G., Chain, F., Martín, R., Bermúdez-Humarán, L. G., Courau, S., \& Langella, P. (2017). Beneficial effects on host energy metabolism of short-chain fatty acids and vitamins produced by commensal and probiotic bacteria. Microbial Cell Factories, 16(1), 79.

Lee, Y. K., \& Puong, K. Y. (2002). Competition for adhesion between probiotics and human gastrointestinal pathogens in the presence of carbohydrate. British Journal of Nutrition, 88(S1), S101-S108.

Linares, D. M., Gómez, C., Renes, E., Fresno, J. M., Tornadijo, M. E., Ross, R. P., et al. (2017). Lactic acid bacteria and bifidobacteria with potential to design natural biofunctional health-promoting dairy foods. Frontiers in Microbiology, 8, 846.

Mao, B., Li, D., Zhao, J., Liu, X., Gu, Z., Chen, Y. Q., ... Chen, W. (2014). In vitro fermentation of lactulose by human gut bacteria. Journal of Agricultural and Food Chemistry, 62(45), 10970-10977.

McSweeney, P. L. H. (2004). Biochemistry of cheese ripening. International Journal of Dairy Technology, 57(2-3), 127-144.

Minervini, F., Siragusa, S., Faccia, M., Dal Bello, F., Gobbetti, M., \& De Angelis, M. (2012). Manufacture of Fior di Latte cheese by incorporation of probiotic lactobacilli. Journal of Dairy Science, 95(2), 508-520.

Moens, F., Verce, M., \& De Vuyst, L. (2017). Lactate- and acetate-based cross-feeding interactions between selected strains of lactobacilli, bifidobacteria and colon bacteria in the presence of inulin-type fructans. International Journal of Food Microbiology, 241, 225-236.

National Committee for Clinical and Laboratory Standards (NCCLS) (2012). Performance Standards for Antimicrobial Disc Susceptibility Test. Wayne, Pa, USA: National Committee for Clinical Laboratory Standards Institute.

O'Sullivan, O., \& Cotter, P. D. (2017). Microbiota of raw milk and raw milk cheeses. In (4th ed.). P. L. H. McSweeney, P. F. Fox, P. D. Cotter, \& D. W. Everett (Vol. Eds.), Cheese: Vol. 12, (pp. 301-316). San Diego, CA, USA: Academic Press.

Ríos-Covián, D., Ruas-Madiedo, P., Margolles, A., Gueimonde, M., de los Reyes-Gavilán, C. G., \& Salazar, N. (2016). Intestinal short chain fatty acids and their link with diet and human health. Frontiers in Microbiology, 7, 185.

Ruiz-Moyano, S., Martín, A., Benito, M. J., Nevado, F. P., \& Córdoba, M. G. (2008). Screening of lactic acid bacteria and bifidobacteria for potential probiotic use in Iberian dry fermented sausages. Meat Science, 80(3), 715-721.

Russell, W. R., Hoyles, L., Flint, H. J., \& Dumas, M. E. (2013). Colonic bacterial metabolites and human health. Current Opinion in Microbiology, 16(3), 246-254.

Sharma, S., \& Kanwar, S. S. (2018). Effect of prebiotics on growth behaviour of Lactobacillus plantarum and their impact on adherence of strict anaerobic pathogens to intestinal cell lines. Journal of Food Safety, 38(1), e12384.

Sharma, P., Tomar, S. K., Goswami, P., Sangwan, V., \& Singh, R. (2014). Antibiotic resistance among commercially available probiotics. Food Research International, 57, $176-195$.

Tripathi, M. K., \& Giri, S. K. (2014). Probiotic functional foods: Survival of probiotics during processing and storage. Journal of Functional Foods, 9, 225-241.

Vasiljevic, T., \& Shah, N. P. (2008). Probiotics—from Metchnikoff to bioactives. International Dairy Journal, 18(7), 714-728.

Vilela, E. G., Torres, H. O. G., Ferrari, M. L. A., Lima, A. S., \& Cunha, A. S. (2008). Gut permeability to lactulose and mannitol differs in treated Crohn's disease and celiac disease patients and healthy subjects. Brazilian Journal of Medical and Biological Research, 41(12), 1105-1109.

Xu, H., Jeong, H. S., Lee, H. Y., \& Ahn, J. (2009). Assessment of cell surface properties and adhesion potential of selected probiotic strains. Letters in Applied Microbiology, 49(4), 434-442.

Zoumpopoulou, G., Tzouvanou, A., Mavrogonatou, E., Alexandraki, V., Georgalaki, M., Anastasiou, R., et al. (2018). Probiotic features of lactic acid bacteria isolated from a diverse pool of traditional Greek dairy products regarding specific strain-host interactions. Probiotics and Antimicrobial Proteins, 10(2), 313-322. 